\title{
A Study on Empowering Employee Capabilities Towards Organizational Excellence
}

\author{
Kokila Mohan \\ VIT Business School, VIT University \\ Koki.mohan90@gmail.com \\ Dr. Gomathi S. \\ VIT Business School, OB \& HR Team, VIT University, \\ Tamilnadu, India, sgomatthi@vit.ac.in, gommatthi@gmail.com
}

\section{Doi:10.5901/mjss.2014.v5n20p557}

\section{Abstract}

Employee development is an important factor for an Organisational excellence. This study highlights a model for employee development starting from organizational need, planning, design and strategy implementation. An organizational excellence is mainly dependent on its employee capabilities, skills and talents. The model developed by this study aims to improve the employee capabilities in terms of their commitment in the work spot individually and collectively contributing for the achievement of the organizational goals. This is purely a theoretical framework on employee capabilities leading to organizational excellence.

Keywords: Employee development, employee capabilities, organizational excellence

\section{Introduction}

In any industry the employees are considered as the key success factor of the organization. The organization is fully dependent on the employees for its functioning and growth. In that context the employees have to be motivated and developed well in order to increase their job satisfaction and maintain employee retention. In this dynamic world the organizations are struggling to stay in the market with their existing products and operations, they need to change according to the market conditions were they should introduce new technologies and equipments to maintain the standards. Towards the changes the employees were also insisted to improve their skills and capabilities. The organization provides the training in order to improve the employee's individual and technical efficiency. Managing employees is one of the main functions of the human resource department, where they need to help the employees in developing their individual capabilities (learning's, attitude, skills, talent etc.), so they invest more money on employee's development. When the employees skills, learning's, attitude increased it will have great impact on the performance of employees. When the performance of the employee increases which would automatically leads to the organizational excellence. This article explains the employee development model and gives the clear idea on employee development which increases the capabilities and performance of employees to meet the organizational excellence. 
Figure 1. Employee Development Model

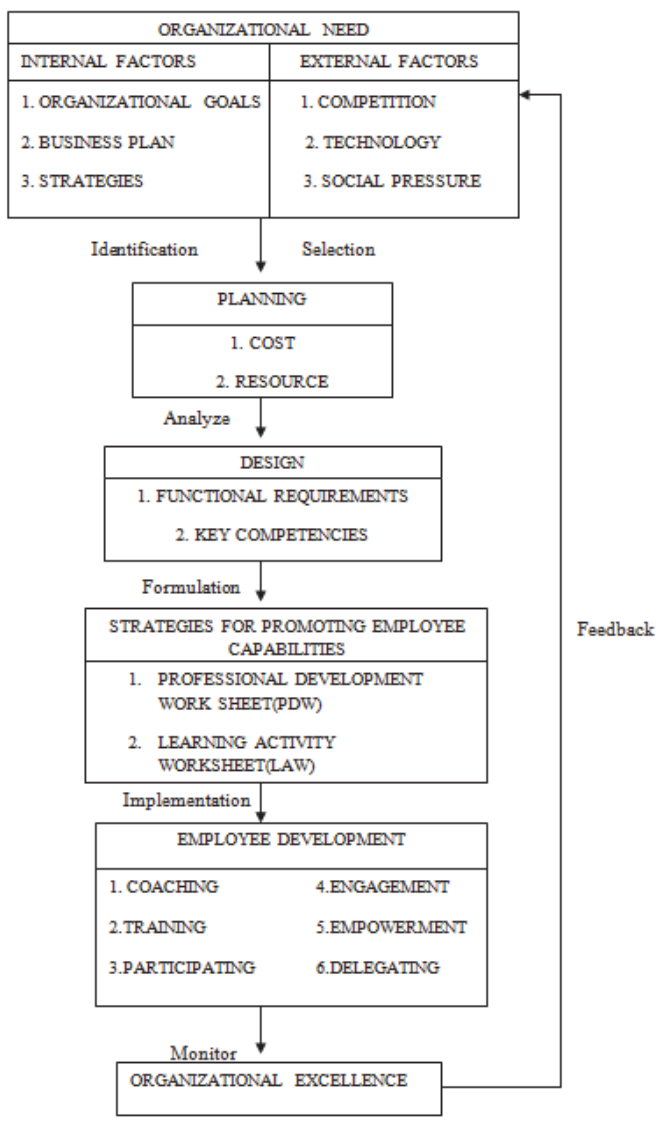

\section{Organizational Need}

The organizational need is defined by both internal and external factors. These factors create a need to the organization to develop themselves towards excellence i.e. the employees are given training to develop themselves and advancement made to the existing processes in the organization to improve its capabilities.

\subsection{Internal Factor}

Internal factors are the factors which creates the need to the organization within its own environment.

Organizational goals

Business plan

Strategies

\subsubsection{Organizational Goals}

The goals of the organization are of short- term and long- term which has estimations and completion periods. To be on the perfect side organizations need to advance their processes and operations in order to achieve their targets on time. 


\subsubsection{Business Plan}

The business plan is the statement which consists of the set of organizational targets and the plans were it has to be achieved in an efficient way. The business Plan may be internally focussed or externally focussed. These plans help the employees to achieve their targets on time and prove their efficiency towards the work.

\subsubsection{Strategies}

The strategy is the framework which clearly defines the organizational needs towards change and development. These strategies are also known as the action plans which fill the gap in the organizational need and it helps in improving the employee's capability.

\subsection{External Factors}

The external factors are the factors which creates the need of employee development outside the organization.

\subsubsection{Competition}

The competition creates the need to the organization and helps them to shape their strategies and the capabilities in order to cope up with the competitors in the dynamic market. So they need to empower their employees which lead to organizational efficiency.

\subsubsection{Technology}

All the organization relies on the technology for their improvement and development. The technology gives access to enormous opportunities for business development. Where these technology becomes an essential element for any business for its success.

\subsubsection{Social Pressure}

The social pressure has the influence on the organizational development and helps the organization to empower its efficiency in order to fulfill its needs and improve the employee productivity. It includes peer group pressure, culture in the organization etc.

\section{Planning}

Planning is a framework and a process of thinking which deals with organizing things to achieve the goals and objectives of the organization. This planning process involves all the activities of the organization and helps the people in understanding the goals and objectives which can be achieved in a stipulated time period and it act as a guideline to the organization in achieving targets.

\subsection{Cost}

The activities associated with the employee development program are providing training to employees, coaching, empowering, delegating etc. there will be cost involved with these programs and those costs should be planned before execution. All the developmental plans involved cost and those costs should be estimated in order to predict the future.

\subsection{Resource}

The various resources in the organization are manpower, material, money, machinery etc. where these resources need to be planned before involving it in the developmental process. The main resource in the organization is manpower requirement (unskilled labour, skilled labour, professional and managerial) which is used to increase the organizational efficiency through providing the efficient employees to the organization. 


\section{Design}

Based on the planning process the design of the program should be framed and developed which will create an impact on the employee developmental program.

\subsection{Functional Requirements}

This functional requirement is the part of design process which helps the organization to know about their requirements in developing the employee's capability, encourage the employees and to enhance them in the organizational activities.

\subsection{Key Competencies}

Key competencies of the employees are analyzed clearly and the design should frame on the analyzed results, so that it will fill the gap and helps in enhancing the employees to develop their skill, knowledge and learning.

\section{Strategies for Promoting Employee Capabilities}

The designed model should be implemented by the organization, so these strategies are followed by them to develop those designs into an action plan. The strategies are;

\subsection{Professional Development Worksheet (PDW)}

The professional development work sheet helps an organisation to identify the employee development need and creates the association into an action plan. This strategy involves various factors embedded in it they are; gaining selfawareness, seeking outside input, developing action plan, setting longer term goals etc.

\subsection{Learning Activity Worksheet (LAW)}

The learning activity worksheet is used by the organization after providing various training events to the employees. Thereby employees are given suggestions on their training program and the gaps are filled by developing the strategies framed by the organization.

\section{Employee Development}

Employee development is encouraging employees by training them and helping them to acquire new knowledge and skill in order to make them perfect in this changing environment. And also it enhance them to feel their importance in all decision making process. Various employee development process are involved they are,

\subsection{Coaching}

Coaching is developmental processes were the employees are supported and facilitated to achieve their specific targets and goals. The expertized person in the area guides the employees in this process. This coaching enables the employees and the organization to achieve their full potential and targets and it increases the employee commitment towards the work.

\subsection{Training}

Training is teaching the specific skills, knowledge and capabilities to the employees in order to perform their tasks efficiently. This training is conducted by the organization to develop the employees and to empower them in the modern technology, techniques, and tools.

\subsection{Participating}

Employee participation encourages the employees to involve in the decision making process and encourage them to take 
responsibilities in developmental activities carried out by the organization. This employee participation is the part of employee development model and it act as the motivational tool to enhance employees.

\subsection{Engagement}

Employee engagement is a framework which is designed to find the employees commitment towards the organizational goals and values which will also lead to Organisation success.

\subsection{Empowerment}

Empowerment is enhancing and encouraging the employees to develop their skills and knowledge in a particular organization. Were the employees are given chance to express their views on the decision made and improve their ability to make decisions on their own.

\subsection{Delegating}

Delegating is the act of assigning tasks to the employee by the manager or the supervisor were this helps the employees to make their presence in the managerial role and in the operations of the organization which helps in motivating them towards the work.

\section{Organizational Excellence}

Organizational excellence is an integrated approach of organizational development and performance management. Which mainly focuses on the empowerment and enhancement of employees were they can improve their capabilities and make them more skillful to manage the change in the organization. And this will lead the organization to perform excellent towards the standards.

\section{Conclusion}

Employee Development is a continuous process in any Organization. The development of an employee cannot be made overnight, it is a systematic process of planning organization need, designing and formulating strategy for employee development by sharpening their capabilities which in turn tones up the productivity for achieving Organizational excellence. This paper highlights the methodological preparation of employees for facing the challenges in future innovatively for updating the technology like robotics which implies a strong fact that it cannot replace human beings who are very dynamic and sensible to the environment.

\section{References}

Abdul Hameed and Aamer Waheed, (2011). "Employee development and its affect on Employee Performance- A Conceptual Framework", International journal of business and social science, Vol.2. No.13 p 224-229.

Ajit Kumar Ghosh,(2013), "Employee Empowerment: A Strategic Tool to obtain Sustainable Competitive Advantage", International Journal of Management Vol. 30 No. 3 Part 1 2013, p $95-107$

Amarjit Gill, Suraj P. Sharma, Neil Mathur and Smita Bhutani, "The Effects of Job Satisfaction and Work Experience on Employee-Desire for Empowerment: A Comparative Study in Canada and India", International Journal of Management Vol. 29 No. 1 Part 1 Mar 2012 p 190-200

Chay Hoon Lee and Norman T. Bruvold, (2003). "Creating value for employees: investment in employee development, Int. J. of Human Resource Management Vol.14 №. 6 p 981-1000.

Cristina Simón and Gayle Allard, "Competitiveness and the employment relationship in Europe: Is there a global missing link in HRM?", Advances in International Management, Volume: 21, 2008

David Elloy,(2012), "Effects of Ability Utilization, Job Influence and Organization Commitment on Employee Empowerment: An Empirical Study", International Journal of Management Vol. 29 No. 2 Part 2 June 2012, p 627-632

David Taylor and David Edge, "Personal development plans: unlocking the future", Career Development International 2/1 [1997] p 21-23

Fred C. Lunenburg, "Human Resource Planning: Forecasting Demand and Supply", International Journal of Management, Business, and Administration Volume 15, Number 1, 2012

H. Ongori and J.P.W. Shunda, "Managing Behind the Scenes: Employee Empowerment", International Journal of Applied Economics and Finance 2(2): p 84-94, (2008) ISSN 1991-0886 
Inger G. Stensaker and Christine B. Meyer, "Change experience and employee reactions: developing capabilities for change", Personnel Review Vol. 41 No. 1, 2012 pp. 106-124

Job P. Antony and Sanghamitra Bhattacharyya, "Measuring organizational performance and organizational excellence of SMEs - Part 2: an empirical study on SMEs in India", Measuring Business Excellence Volume: 14 Issue: 32010

Marion Lambert and Josiane Vero, "The capability to aspire for continuing training in France: The role of the environment shaped by corporate training policy", International Journal of Manpower Volume 34 issue 4, ISSN 0143-7720

Nick Bontis, Alexander Serenko, "The moderating role of human capital management practices on employee capabilities", Journal of Knowledge Management Volume: 11 Issue: 32007

Pamela Jewett and Deborah MacPhee, "A dialogic conception of learning: collaborative peer coaching", International Journal of Mentoring and Coaching in Education Volume: 1 Issue: 12012

Petra Horvathova and Marie, "Acquisition of Talents from Organization's Internal Sources", International Conference on Business and Economics Research, vol.1 (2011) p5-9

Priya Shanmugam, R. Krishnaveni, "employee engagement: an introspection into its conceptualisation", International Journal of Social Science \& Interdisciplinary Research vol.1 issue 9, September 2012, ISSN 22773630

R. Ganesan and Pathak Gauri, (2012). "Development of an empirical model to map motivators to deeply embedded life interests as a strategy for improving employee performance through job sculpting", Procedia - Social and Behavioral Sciences vol. 58 p 331 339

Rachel Lofthouse and David Leat, "An activity theory perspective on peer coaching", International Journal of Mentoring and Coaching in Education Volume: 2 Issue: 12013

Soonhee Kim, Hyangsoo Lee, "Factors affecting employee knowledge acquisition and application capabilities", Asia-Pacific Journal of Business Administration Volume: 2 Issue: 22010

Subodh P. Kulkarni , "Sustaining the equality of employee voice: a dynamic capability", International Journal of Organizational Analysis Volume: 18 Issue: 42010 